\title{
Microstructures of $\mathrm{CaSO}_{3} 0 \cdot 5 \mathrm{H}_{2} \mathrm{O}$ single crystals grown in silica gel
}

\author{
S N PATIL and A VENKATESWARA RAO \\ Department of Physics, Shivaji University, Kolhapur 416004, India \\ MS received 30 July 1990; revised 18 December 1990

\begin{abstract}
This paper deals with the study of surface structures of silica gel grown crystals of $\mathrm{CaSO}_{3} 0.5 \mathrm{H}_{2} \mathrm{O}$. Various growth features such as growth layers, overgrowths and oriented and random liquid inclusions have been observed using optical and scanning electron micro-
\end{abstract} \\ scopy techniques.
}

Keywords. Surface structure; silica gel.

\section{Introduction}

Microstructure studies of single crystals are useful for understanding the mechanism of crystal growth. Although the microtopographical structures on different faces of a crystal represent the conditions at the termination of growth, correlations of such structures on different faces give information about the history of growth of the crystals. Observation of the microstructures is also useful for geologists as the crystallization processes in the laboratory have similarities with those in nature. Thus the study of growth mechanism of crystals grown in gels might help in understanding the growth mechanism of rock-forming materials.

The study of microstructures of various crystals led Kossel (1927) and Stransky (1928) to put forward, independently, a two-dimensional nucleation theory for the growth of crystals. Studies of surface structures on crystal faces have also proved helpful in establishing a screw dislocation theory of crystal growth and interpreting information concerning the structure and behaviour of dislocations in crystals (Frank 1949).

We had earlier studied the gel growth and characterization of $\mathrm{CaSO}_{3} 0.5 \mathrm{H}_{2} \mathrm{O}$ single crystals (Patil and Rao 1990a,b). The present paper deals with investigation on the surface structures of silica gel grown crystals of $\mathrm{CaSO}_{3} 0 \cdot 5 \mathrm{H}_{2} \mathrm{O}$ to understand the mechanism of its growth.

\section{Experimental procedures}

Calcium sulphite crystals were grown in silica gel at room temperature at a $\mathrm{pH}$ value of 4.5 using various concentrations of feed solutions of $\mathrm{Na}_{2} \mathrm{SO}_{3}$ ranging from 0.1 to $1 \mathrm{M}$. Transparent crystals bounded by $\{001\},\{101\}$ and $\{210\}$ faces were obtained from diffusion of the two reactants of $\mathrm{CaCl}_{2}$ and $\mathrm{Na}_{2} \mathrm{SO}_{3}$ as described earlier (Patil and Rao 1990a,b). The crystals, thoroughly cleaned with ethyl alcohol, were coated with silver films in a vacuum coating unit and examined under metallurgical and scanning electron microscope (SEM). 


\section{Observations and discussion}

\subsection{Spiral growth}

Crystals obtained using feed solutions of low concentration (below $0.2 \mathrm{M}$ ) showed the presence of spiral structures on $\{001\}$ faces as shown in figure 1 . At lower concentration of the feed solution, $\{001\}$ faces are the slowest growing faces and hence are larger in size than the $\{210\}$ and $\{101\}$ faces. Observations of growth spirals on $\{001\}$ faces of calcium sulphite crystals at lower concentrations of feed solutions suggest that these faces might have grown by the spiral growth mechanism. It is suggested that as growth proceeds, internal stresses develop giving rise to slip steps producing screw ledges on these faces and growth around such ledges and resulting in spiral turns.

\subsection{Growth layers from the edges of large steps on the crystal}

The edges of the crystal or large steps on the crystal surface sometimes work as elegant centres for initiation of growth layers. Several examples illustrating this effect were observed on the $\{001\}$ faces of crystals grown in silica gels using $\mathrm{CaCl}_{2}$ and $\mathrm{Na}_{2} \mathrm{SO}_{3}$ as the reactants. Figure 2 shows the SEM photograph of a typical crystal of $\mathrm{CaCO}_{3} 0.5 \mathrm{H}_{2} \mathrm{O}$. The growth layers on the $\{001\}$ face of $\mathrm{CaSO}_{3} 0.5 \mathrm{H}_{2} \mathrm{O}$ crystal are clearly seen at a higher magnification using SEM in figure 3. Sometimes growth layers start from all sides of a crystal face and advance towards the centre of the face (figure 4). Figure 4 shows a build-up of material on the crystal edges with a fill-in towards the centre indicating that edge nucleation was the predominant growth mechanism at higher concentrated feed solutions.

The occurrence of step imperfections is a common feature observed on srystals grown with $1.5 \mathrm{M}$ feed solutions and often layers originate from the imperfections on the steps. An example is provided in figure 4 where step imperfections initiate growth layers.

\subsection{Growth layers from liquid inclusions}

Inclusions and tiny misoriented crystals do have their influence on the spreading of growth sheets on the host crystal face (Sunagawa 1953). The most typical and widely observed growth pattern of such type is the one which looks like the back current formed behind a rock is a stream. Figure 5 is an example of such a pattern derived from the two-dimensional nature of spreading of growth layers. If growth continues, liquid drops or impurities may get covered by the growth layers in which case they get embedded in the body of the crystal affecting the perfection.

\subsection{Overgrowths on the crystal surfaces}

Sometimes overgrowth of quite a large size (from a few angstroms to a few microns) were observed to be grown on the $\{001\}$ faces of the host (primary) crystals. Figure 6 shows overgrowth on the $\{001\}$ face in the form of square structure. According to 

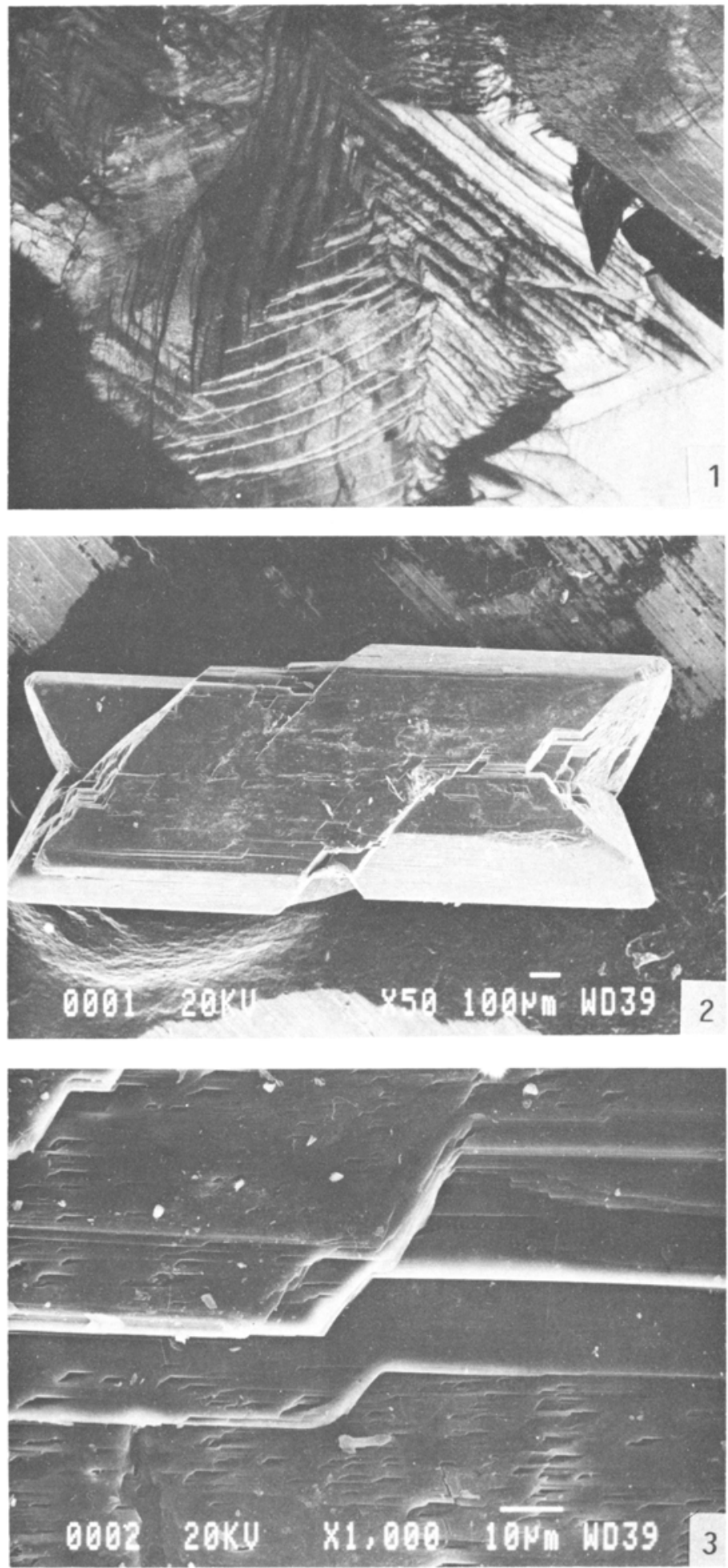

Figures 1-3. 1. Triangular growth spiral layer in $\{001\}$ face of a $\mathrm{CaSO}_{3}$ crystal. 2. Typical crystal habit of $\mathrm{CaSO}_{3}$ using SEM under low magnification $(\times 50)$. 3. Growth layers and each pits on the surface of $\mathrm{CaSO}_{3}$ crystal using SEM $(\times 1000)$. 

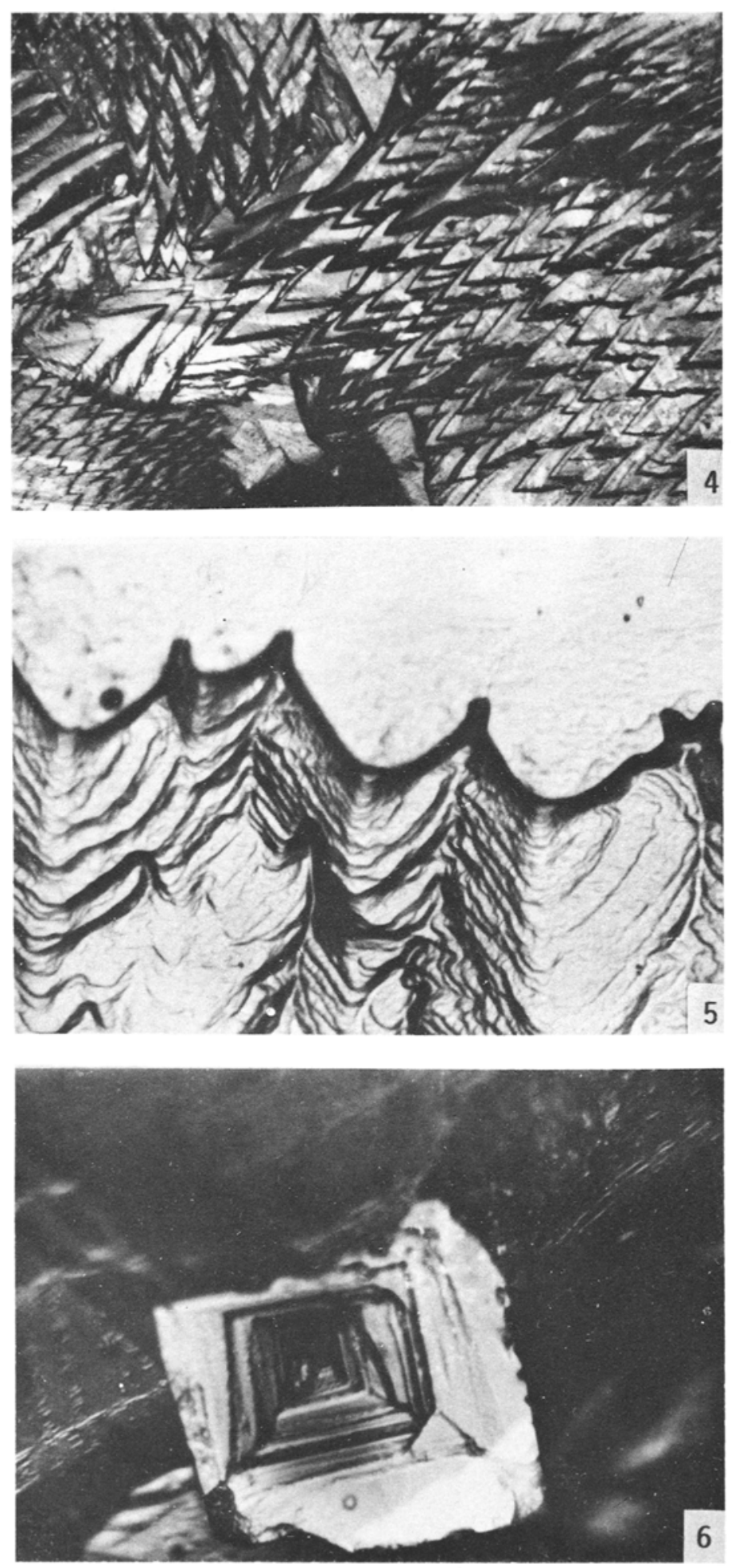

Figures 4-6. 4. Starting of growth layers from all sides of a crystal face advancing towards the centre of the face. 5. Initiation of growth layers from small liquid inclusions. 6. Overgrowth on the $\{001\}$ face in the form of a square. 


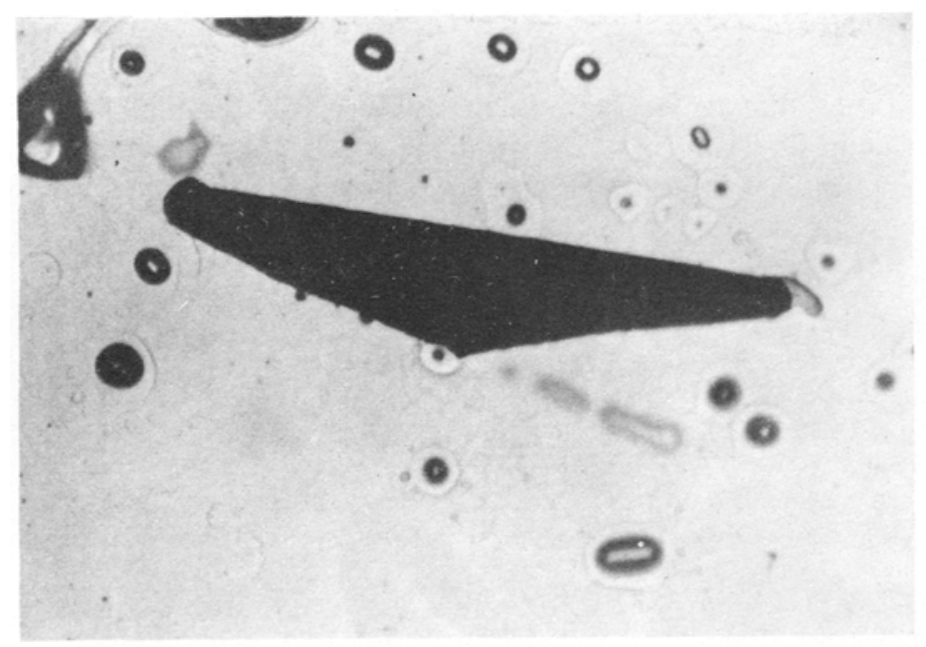

Figure 7. A typical triangular liquid inclusion observed on $\{001\}$ face on $\mathrm{CaSO}_{3}$ crystal.

Buckley (1951) overgrowth occurs due to interruptions in the continuity of deposition which in turn is due to change in growth conditions, such as temperature changes or the temporary exhaustion of a solution after an active burst of crystallization.

\subsection{Liquid inclusions}

An example of liquid inclusions on the $\{001\}$ face of a crystal is shown in figure 7. These inclusions are advancing along the $\{001\}$ direction. That the inclusions show a tendency to have $\{010\}$ indicates that the surface energy of the $\{010\}$ is less than that of any other plane. This indication agrees with the views of Seitz (1940) and Wagner and Franklin (1963).

Liquid inclusions are produced when an area of a crystal face ceases to grow while the neighbouring areas continue to grow normally and after some time the available liquid is enclosed. The reason for cessation of growth may be adsorption of some impurity or some minor fluctuations in temperature during growth (StricklandConstable 1973). The liquid trapped in the crystals is probably sodium chloride resulting from the by-product or reaction waste product during crystallization of $\mathrm{CaSO}_{3} 0 \cdot 5 \mathrm{H}_{2} \mathrm{O}$.

\section{Conclusions}

It has been observed that at very low concentrated feed solutions, the crystals were grown by screw dislocation mechanism. At higher concentrated feed solutions, layer growth mechanism is predominant. The growth layers initiate from the edge steps and inclusions on the crystal surface. Overgrowths of square and spinal cord type structures have been observed on host crystal faces. The liquid entrapment is the main source of crystal defects in gel-grown $\mathrm{CaSO}_{3} 0 \cdot 5 \mathrm{H}_{2} \mathrm{O}$ crystals. 


\section{Acknowledgements}

The authors are grateful to Dr Tyagarajan of RSIC, IIT, Bombay for X-ray analysis of the crystals and Dr Pinto of TIFR, Bombay for SEM. We are thankful to Shri S K Sutar for technical help. SNP thanks the University authorities for a Fellowship.

\section{References}

Buckley H E 1951 Cryst. Growth

Frank F C 1949 Disc. Faraday Soc. 548.

Kossel W 1927 Nachr. Akad. Wiss. Gottingen, Mattr. Phys. Klasse, p. 135

Patil S N and Venkateswara Rao A 1990a Cryst. Res. Technol. (to be published)

Patil S N and Venkateswara Rao A 1990b Cryst. Res. Technol. (to be published)

Seitz F 1940 Modern theory of solids (New York)

Stransky I N 1928 Z. Phys. Chem. 136259

Strickland-Constable R F 1973 Kinetics of crystallization (New York: Academic Press)

Sunagawa I 1953 Colloques Internationaux du centre national de la recheche Scientifique, No. 152

Wagner J B and Franklin W 1963 J. Appl. Phys. 343121 